\title{
Survey of the demand for care services for older people and the training needs of their care workers: a cross-sectional study in Northeast China
}

\author{
Shuqin $\mathrm{Li}^{1}$, Jun Zhang ${ }^{1}$, Yan Liu', Ai-ping Wang ${ }^{1 *}$ and Guixing Qiu ${ }^{2}$
}

\begin{abstract}
Background: The older population is increasingly utilizing professional healthcare services, while the requirements for caregivers are becoming more demanding. Therefore, it is important to be mindful not only of the service needs of older people but also to consider the training needs of their care workers. The present study aimed to investigate the care service needs for older people and the training needs of their care workers.

Methods: A cross-sectional questionnaire was used to survey 589 residents of 6 nursing homes and 2 geriatric hospitals, 415 medical staff from 7 geriatric hospitals, 5 nursing homes, and 1 community institution, and 372 nursing assistants from 21 nursing institutions in northeast China.

Results: The service with the greatest demand and that with which users were most satisfied was regular visits by healthcare personnel, which was the case for $87.27 \%$ of the care recipients. Of the medical staff, $75.42 \%$ had training needs related to geriatric healthcare, while the most requested training content was the comprehensive assessment of old people. The most requested method for the delivery of training was by self-study online video courses. Of nursing assistants, only $53.4 \%$ had obtained the relevant practicing certificate. While $83.6 \%$ participated in relevant training, $86 \%$ expressed the need for additional training. The majority of this category of staff wished to receive training in everyday care routines, and the majority wanted to learn by way of practical training.
\end{abstract}

Conclusions: The care needs of the older population are diverse, and the work performed by healthcare personnel is increasing in scope. The existing training system for such care personnel is not perfect, and the demand for training is high. Existing training methods and content require improvement.

Keywords: Geriatric care, Old-age service, Service demand, Care workers, Training needs

\section{Introduction}

It is clear that the global population is aging. Over the period 2015-2050, it is estimated that the proportion of the global population aged 60 and above will almost double, from $12-22 \%$ [1]. In 2020, 180 million of the

\footnotetext{
* Correspondence: jianghaoran88@hotmail.com

1 Department of Nursing, First Affiliated Hospital of China Medical University, Liaoning, Shenyang, China

Full list of author information is available at the end of the article
}

population were aged 65 and above in China, accounting for approximately $13 \%$ of the total population. It is estimated that by 2035 , the number aged 65 and above in China will reach 310 million and 380 million by 2050, accounting for $22.3 \%$ and $27.9 \%$ of the total population, respectively [2]. With such numbers increasing inexorably, the numbers of older people requiring long-term care will also increase significantly. In addition, the overall numbers of disabled people are increasing rapidly in China, and are

(c) The Author(s). 2022 Open Access This article is licensed under a Creative Commons Attribution 4.0 International License, which permits use, sharing, adaptation, distribution and reproduction in any medium or format, as long as you give appropriate credit to the original author(s) and the source, provide a link to the Creative Commons licence, and indicate if changes were made. The images or other third party material in this article are included in the article's Creative Commons licence, unless indicated otherwise in a credit line to the material. If material is not included in the article's Creative Commons licence and your intended use is not permitted by statutory regulation or exceeds the permitted use, you will need to obtain permission directly from the copyright holder. To view a copy of this licence, visit http://creativecommons.org/licenses/by/4.0/. The Creative Commons Public Domain Dedication waiver (http://creativecommons.org/publicdomain/zero/1.0/) applies to the data made available in this article, unless otherwise stated in a credit line to the data. 
estimated to grow from 43.75 million in 2020 to 91.4 million in 2050 [3], while approximately $75 \%$ of the older population currently suffers from at least one chronic disease [4]. Satisfying the growing needs of this category of individuals in terms of health and care services represents a considerable challenge $[5,6]$.

At present, care services for older people include informal care provided by family members and formal care provided by institutions such as nursing homes. China's long-standing one-child policy combined with the aging of the population has led to a rise in the dependency ratio, a heavy burden on the young, and a decline in the ability of families to provide adequate care for their aging family members $[7,8]$. In addition, China's expansion of urbanization and large-scale migration of the population make balancing work and providing care for older relatives a challenge for the young. This has resulted in increased numbers of empty nesters in urban and rural areas. Therefore, the older population increasingly has formal care requirements [9]. In addition, with improvements in material and cultural living standards, public opinion and the need for geriatric care have also changed. Traditional informal care services cannot provide a high quality of life for older people, and so they are increasingly utilizing professional geriatric care services [10-12].

As aging of the population becomes more acute, the number of the older population that is disabled, has dementia, or is solitary has increased. The care model of combined medical care and nursing has become an important method of servicing a population that is aging, requiring a higher level of specialization in geriatric care $[13,14]$. High-quality care for older people must be provided by a professional team, but the formation of such care teams in China is far from perfect, especially regarding nursing assistants, reflected by their low level of education and lack of professional knowledge [15]. Therefore, improving the overall quality and skill level of care teams is an important step to providing adequate support. Due to the rapid expansion of the aging population in China, research on the training of healthcare personnel continues to be explored. There is a strategic significance in understanding the current situation and the training demands of healthcare personnel for older people. The key issues need to be identified and the basis for improvements in training systems for healthcare personnel for older people in China require analysis for the future.

According to international standards, aging societies are defined as those in which the population aged 60 or above in a country or region accounts for more than $10 \%$ of the total population or more than $7 \%$ of the population aged 65 or above [16]. The latest national census data indicate that the proportion of the population aged 65 or above in Northeast China is $16.39 \%$, higher than the national average [17]. The present study will analyze the population in Northeast China to investigate their needs for geriatric care services and the training needs of the healthcare personnel, aiming to represent a reference for improvement in the quality of the care services and to satisfy the diverse needs of older people.

\section{Materials and methods}

\section{Study design and participants}

A cross-sectional study was conducted in July and August 2020 among geriatric hospitals, geriatric nursing homes, and communities in northeast China. The directors of each geriatric institution were contacted and asked to include as many participants as possible using a convenient sampling method. A total of 589 residents from 6 geriatric nursing homes and 2 geriatric hospitals, 415 medical staff from 7 geriatric hospitals, 5 geriatric nursing homes, and 1 community institution, and 372 nursing staff from 21 geriatric nursing homes were included in the study. Recipients of care were included if they met the following criteria: (1) Aged 65 and above; (2) Possessing clarity of thinking, ability to express themselves and without any apparent difficulty in communication; (3) Volunteered to participate in the study and provided signed informed consent. Exclusion criteria for older people were as follows: the presence of acute disease of the heart, brain, or kidney, or other disease. The inclusion criteria for medical staff were: (1) Possession of a relevant professional qualification certificate; (2) Working in that institution for more than 6 months; (3) Normally undertaking professional geriatric medical care (treatment / nursing / rehabilitation / health management, etc.). Exclusion criteria for medical staff: (1) Those that had not been on duty for more than 1 month; (2) Interns or trainees; (3) Personnel not directly involved in front-line work. Inclusion criteria for nursing staff: (1) Those working in that institution for more than 3 months; (2) Normally caring for old people. Exclusion criteria for nursing staff were as follows: (1) Those that had not been on duty for more than 1 month; (2) Interns or trainees. The study was approved by the ethics review committee of Peking Union Medical College Hospital, Chinese Academy of Medical Sciences.

\section{Instruments}

Self-designed questionnaires were used in the present study.

\section{Questionnaire for care recipients}

The questionnaire included basic personal information, their requirements for healthcare services, and the status of the services they receive. Personal basic information 
included age, gender, level of education, types of chronic disease, level of self-care (Not dependent: no requirement for others to provide care services; Mildly dependent: others required to take care of a small proportion of daily living needs; Moderately dependent: most daily living needs require others to provide care; Severely dependent: all needs of daily living require the care of others), evaluation of their current physical condition (on a scale from 0 to 100 , where 0 is very poor and 100 is very good), their current type of care institution, reasons for choosing this category, and other care services they wished to receive, etc. Their requirements and the status of the healthcare services they received included five aspects of healthcare services (3 items), medical care services (3 items), rehabilitation guidance services (2 items), psychological/spiritual support services (1 item), and recreational activities (1 item), for a total of 10 items, each having 5 options for the evaluation of demand (really not required, not required, neutral, required, very much required) and status (very dissatisfied, dissatisfied, neutral, satisfied, very satisfied).

\section{Questionnaire for medical staff}

The questionnaire included four parts: personal basic information, understanding of the geriatric healthcare industry, training experience, and required training. Personal basic information included age, gender, level of education, work title, number of years worked, etc. Questions about their understanding of the geriatric healthcare industry included 8 items: degree major subject, whether courses associated with care of the elderly were studied, satisfaction with their job and income, why this profession was chosen, what training the respondent considered was still required, and the types of professionals and services urgently required. Questions about training experience included 7 items, such as whether the employee had received training relevant to geriatric healthcare, content of the training, whether relevant assessment had been conducted, and the type of assessment performed. Questions about training requirements included 8 items, including whether additional training is expected, what the anticipated training consists of, the manner in which it should be conducted, problems of the current training, and suggestions for future training.

\section{Questionnaire for nursing staff}

The questionnaire included general information, current working arrangements, training received and training required. General information included age, gender, level of education, and marital status. Work arrangements included whether certification had been obtained, the level of certification, reasons for entering the nursing profession, type of work performed, years worked, daily work schedule, and their evaluation of the difficulty of work.
Questions about training experience included 15 items, including whether any job-related training had been received, the method, content, frequency, and purpose of the training, and any problems in the current training. Training needs included 8 items, such as the extent of training required, how the time required for training was expected to be scheduled, the expected length, mode, frequency, content of training, and suggestions for future training.

\section{Data collection}

Investigators used "Questionnaire Star" software to conduct the online surveys after they had received unified training. They explained the purpose and significance of the study to respondents face to face who then provided signed informed consent after agreeing to participate in the study. Respondents then completed the relevant questionnaire. The questionnaires were designed to save a respondent's answers automatically and to continue from the same point in the questionnaire if the survey was reopened, after scanning the relevant code. Answers to all questions were required prior to submission.

\section{Statistical analysis}

All data were analyzed with SPSS v22.0 software. Nonnormally distributed measurement data were expressed as medians, for example, working years, working days per week of nursing stuff, and the numbers of disabled geriatric individuals they cared for each day. Frequencies and percentages were used for the descriptive statistics of numerical data.

\section{Results}

\section{General information}

A total of 589 care recipients were included in the study, including 501 (85.06\%) in nursing homes, and 88 (14.94\%) in geriatric hospitals, of which 519 (88.12\%) were aged between 65 and 90. In total, 532 (90.32\%) had at least one chronic disease. The self-care dependency of 199 subjects (33.79\%) was mild, moderate in 144 (24.45\%), and severe in 123 (20.88\%). From the self-rated scoring of health status, 286 cases $(48.56 \%)$ scored below 60, 209 (35.48\%) scored 61-80, and 94 (15.96\%) scored 81-100. The three greatest expenses for care receivers were the fixed expenses of the nursing institution, expenses required to employ family nurses, and their everyday living expenses (clothing, meals, etc.).

A total of 415 healthcare staff were included in the study, including 144 doctors (34.7\%), 213 nurses (51.33\%), 34 rehabilitation instructors (8.19\%), and 24 pharmacists and nutritionists (5.78\%) The majority $(82.65 \%)$ were women. A total of $43.86 \%$ were 30 to 39 years of age, $54(13.1 \%)$ had a Masters degree or above, $249(60 \%)$ had a Bachelors degree, 81 (19.52\%) had a 
junior college certificate, while 31 (7.47\%) had received only technical secondary school education or below. There were 157 members of staff $(37.83 \%)$ that had worked for 5 years or less, 105 (25.3\%) had worked for 5-10 years, while $153(36.87 \%)$ had worked for 10 years or more. In total, 256 (5.38\%) had a primary professional title, 125 had (30.12\%) an intermediate professional title, and $37(8.92 \%)$ had gained a senior professional title.

A total of 372 nursing staff were included in the study who were mainly female, accounting for $89 \%$ of the total. The staff was mostly 40 to 60 of age, $87.4 \%$ of the total. A total of $32(8.6 \%)$ had received a university education or above, 215 (57.8\%) had only a junior high school education, 83 (22.3\%) had a technical secondary school / senior high school education, while $42(11.3 \%)$ had only a primary school education or below. In total, $53.5 \%$ had obtained a work qualification certificate, while $74.4 \%$ had a junior title. The median length of working was 2 years, most worked 5 days per week, and the median number of disabled geriatric individuals they cared for was 6. Daily work included providing everyday living care services (92.7\%), nursing assistance (83.6\%), and psychological or spiritual support (69.4\%). Their evaluation of the difficulty of work was moderate.

\section{Requirement for healthcare services}

In total, $88.96 \%$ of care recipients wanted support to be received in nursing homes, apartments for the older population, medical or nursing service centers, or other institutions. The five most common reasons for choosing that retirement category, ranked in order, were the quality of care services (88.12\%), availability of professional medical services (82.00\%), quality of facilities (80.65\%), cost (34.30\%), and proximity to home (22.41\%). The extent of training required was calculated by dividing the number of questionnaires scored as "required" and "very much required" by the total number, and the extent of satisfaction by dividing the number of questionnaires scored "satisfied" and "very satisfied" by the total number. The service with the greatest demand and satisfaction were regular visits by medical staff. The results for other services are displayed in Table 1.

\section{Training status and requirements of medical staff}

From the questionnaires of medical staff, the reasons for choosing the geriatric healthcare profession were that the role matched their university medical training (57.83\%), optimism about the job prospects of working with older people $(41.44 \%)$, post-transfer entry $(9.16 \%)$, and directed training $(8.43 \%)$. The proportion satisfied with their job was $74.2 \%$ while $37.1 \%$ were satisfied with their income. In total, $59.04 \%$ studied geriatric medicine/ nursing in their education, $81.45 \%$ received training after starting their job, while the principal method of receiving the relevant training was by lectures in units (66.51\%), with $75.42 \%$ requiring additional training in geriatric healthcare. Suggestions included paying attention to the psychological health of care receivers, and governmental and relevant institutions providing greater support and being able to learn advanced technologies both nationally and internationally, etc. The expected content and methods of training are detailed in Table 2.

\section{Training status and the requirements of nursing staff}

During employment, $83.6 \%$ of nursing staff participated in relevant training, with training provided usually once a month, for $62.4 \%$ of staff. The principal purpose of the training was to improve work skills $(87.1 \%)$ and to obtain relevant practicing certification (53.4\%). The training mainly included everyday living care services (92.0\%), nursing assistance (83.0\%), professional ethics (72.7\%), communication skills (72.7\%), rehabilitation services (66.6\%), psychological support (61.7\%), and laws and regulations $(62.4 \%)$. In total, $85.6 \%$ thought the training was easy to understand, $53.4 \%$ thought the training was helpful for work, although only $38.9 \%$ were very satisfied with the training. Problems with the current training were principally the lack of training

Table 1 Extent of demand for healthcare services and satisfaction of recipients

\begin{tabular}{|c|c|c|}
\hline & Demand (\%) & Satisfaction (\%) \\
\hline Medical staff making regular visits & 87.27 & 87.27 \\
\hline Assistance with referrals and emergency ambulance services & 82.85 & 84.55 \\
\hline Regular physical examination and health education activities & 82.51 & 83.36 \\
\hline Providing professional rehabilitation assistance consultation, guidance, training & 82.51 & 81.83 \\
\hline Volunteer accompaniment, environmental adaptation, emotional counseling & 81.66 & 80.98 \\
\hline Providing and equipping with appropriate rehabilitation equipment & 77.25 & 78.78 \\
\hline Assistance in maintaining personal and household hygiene & 76.06 & 87.10 \\
\hline Escrow goods, agency, and other services & 69.78 & 83.02 \\
\hline Assistance in feeding, medical treatment, and other activities & 69.44 & 85.74 \\
\hline Organizing cultural and entertainment activities & 68.08 & 79.63 \\
\hline
\end{tabular}


Table 2 Training needs of medical staff

\begin{tabular}{|c|c|c|}
\hline & Number & Proportion (\%) \\
\hline \multicolumn{3}{|c|}{ 1. Your requirements for training related to geriatric healthcare: } \\
\hline Really not required & 4 & 0.96 \\
\hline Not required & 5 & 1.2 \\
\hline Neutral & 93 & 22.41 \\
\hline Required & 232 & 55.9 \\
\hline Very much required & 81 & 19.52 \\
\hline \multicolumn{3}{|l|}{ 2. Do you think the training satisfied your needs? } \\
\hline Very dissatisfied & 6 & 1.45 \\
\hline Dissatisfied & 20 & 4.82 \\
\hline Neutral & 109 & 26.27 \\
\hline Satisfied & 194 & 46.75 \\
\hline Very satisfied & 86 & 20.72 \\
\hline \multicolumn{3}{|c|}{ 3. Can the existing training solve problems encountered during work? } \\
\hline Completely cannot solve & 1 & 0.24 \\
\hline Mostly cannot solve & 17 & 4.1 \\
\hline Neutral & 121 & 29.16 \\
\hline Mostly can solve & 215 & 51.81 \\
\hline Completely can solve & 61 & 14.7 \\
\hline \multicolumn{3}{|l|}{ 4. Should training content be increased? } \\
\hline Yes & 302 & 72.77 \\
\hline No & 113 & 27.23 \\
\hline \multicolumn{3}{|l|}{ 5. What training content should be added? } \\
\hline Comprehensive geriatric assessment & 198 & 47.71 \\
\hline Geriatric rehabilitation healthcare & 186 & 44.82 \\
\hline Chronic disease management & 185 & 44.58 \\
\hline Geriatric nutrition & 172 & 41.45 \\
\hline Geriatric nursing technology & 148 & 35.66 \\
\hline Geriatric physiology & 147 & 35.42 \\
\hline Humanistic geriatric care & 143 & 34.46 \\
\hline Health education & 137 & 33.01 \\
\hline Risk management and prevention & 115 & 27.71 \\
\hline Professional ethics and laws and regulations & 84 & 20.24 \\
\hline Operation management & 63 & 15.18 \\
\hline Scientific research & 60 & 14.46 \\
\hline \multicolumn{3}{|l|}{ 6. How should training be conducted? } \\
\hline Self-study online video courses & 297 & 71.57 \\
\hline Work hours used to focus on training & 194 & 46.75 \\
\hline Intensive training during spare time & 112 & 26.75 \\
\hline \multicolumn{3}{|l|}{ 7. What are the current training problems? } \\
\hline Lack of training opportunities & 189 & 45.54 \\
\hline Single training methods & 159 & 38.31 \\
\hline Duration of training time or location is inappropriate & 158 & 38.07 \\
\hline Training content is not practical & 78 & 18.8 \\
\hline Trainers are not sufficiently professional & 46 & 11.08 \\
\hline Other & 22 & 5.3 \\
\hline
\end{tabular}

opportunities $(40.8 \%)$ and inappropriate duration or location of training (35.7\%). The main reasons for not participating in training were the inappropriate time the training was provided (46.2\%), and the need to pay for training expenses (38.5\%). Additional training was required by $86 \%$ of respondents. The required training and the methods of delivery are detailed in Table 3.

\section{Discussion}

The present study demonstrates that the older population has a greater demand than currently provided for medical and healthcare services, such as regular visits, assistance for referrals, emergency assistance services, and regular physical examination. The availability of professional medical services ranked second as a reason for choosing the category of institution selected for the provision of care services, possibly related to the majority of residents having chronic diseases and poor physical health. In this survey, $90.32 \%$ of care recipients had chronic diseases, $79.12 \%$ had an inability to administer self-care, while almost half had a self-rated health status score lower than 60 points. These results are consistent with the study of $\mathrm{Han} \mathrm{Hu}$ [18] and demonstrates that China has the largest number of their aging population in need of long-term care, with $70 \%$ having a chronic disease. Secondly, services in high demand are professional rehabilitation assistance consultation, guidance, and training, etc. As a group with a high incidence of physical dysfunction and disablement, old people often require professional rehabilitation training to promote physical recovery, reflected in the survey results, which demonstrated that there was a high demand for rehabilitation guidance services $[19,20]$. The requirement for spiritual and psychological consolation was as high as $81.66 \%$, indicating that the older population has a greater requirement for care services. In addition to traditional financial support, assistance with daily living and other old-age care activities, spiritual problems of the older population have become increasingly prominent. Aging individuals not only require physical health, but also have diverse spiritual needs, spiritual and interpersonal communication requirements, cultural entertainment, etc., that reflect their own values [21, 22]. In terms of mental care, geriatric care institutions provide environmental adaptation, care visits, life companionship, emotional and psychological counseling, and other services to improve the overall quality of life of older people [23].

At present, there are more than 40 million disabled or semi-disabled geriatric individuals in China, and so there is increasing demand for caregivers [24]. There is an urgent need for healthcare professionals with knowledge of medicine, psychology, physiology, sociology, etc. [25]. In the present survey, it was found that $78.3 \%$ of medical 
Table 3 Training requirements for nursing staff

\begin{tabular}{|c|c|c|}
\hline & Number & Proportion \\
\hline \multicolumn{3}{|l|}{ 1. Requirments for training: } \\
\hline Very much not required & 1 & 0.3 \\
\hline Not required & 7 & 1.9 \\
\hline general & 44 & 11.8 \\
\hline Required & 225 & 60.5 \\
\hline Very much required & 95 & 25.5 \\
\hline \multicolumn{3}{|l|}{ 2. How should training be provided? } \\
\hline One-time training & 81 & 21.8 \\
\hline Phased training & 291 & 78.2 \\
\hline \multicolumn{3}{|c|}{$\begin{array}{l}\text { 3. During work, the frequency of ongoing training that should be } \\
\text { provided is: }\end{array}$} \\
\hline Once a month & 127 & 34.1 \\
\hline Once a quarter & 143 & 38.4 \\
\hline Once every six months & 79 & 21.2 \\
\hline Once a year & 23 & 6.2 \\
\hline \multicolumn{3}{|l|}{ 4. After work, the duration of training should be: } \\
\hline Less than $30 \mathrm{~min}$ & 56 & 15.1 \\
\hline $30-60 \mathrm{~min}$ & 210 & 56.5 \\
\hline $61-90 \mathrm{~min}$ & 88 & 23.7 \\
\hline $61-90 \min$ & 13 & 3.5 \\
\hline More than $120 \mathrm{~min}$ & 5 & 1.3 \\
\hline \multicolumn{3}{|l|}{ 5. What type of training is most required? } \\
\hline $\begin{array}{l}\text { Everyday living assistance (catering, cleaning, } \\
\text { bathing, travel, etc.) }\end{array}$ & 290 & 78 \\
\hline $\begin{array}{l}\text { Nursing assistance (basic nursing, such as } \\
\text { turning over, skin protection, etc.) }\end{array}$ & 263 & 70.7 \\
\hline $\begin{array}{l}\text { Rehabilitation services (assisting in rehabilitation } \\
\text { training) }\end{array}$ & 25 & 67.2 \\
\hline $\begin{array}{l}\text { Professional ethics (workflow, professional } \\
\text { standards, professional norms) }\end{array}$ & 273 & 73.4 \\
\hline $\begin{array}{l}\text { Laws and regulations (relevant laws and } \\
\text { regulations for nursing staff) }\end{array}$ & 258 & 69.4 \\
\hline Communication skills & 265 & 71.2 \\
\hline Mental and psychological support & 213 & 57.3 \\
\hline \multicolumn{3}{|l|}{ 6. How should training be conducted? } \\
\hline Practical training & 312 & 83.9 \\
\hline Theoretical lecture training & 285 & 76.6 \\
\hline Network teaching and training & 258 & 69.4 \\
\hline Colleague experience sharing & 180 & 48.4 \\
\hline On site observation & 120 & 32.3 \\
\hline
\end{tabular}

staff in healthcare institutions have training needs, and $72.77 \%$ require increased training content. Previous studies have also shown that the current training cannot meet the growing multi-level and diversified needs of geriatric health and care services [26, 27]. It is also challenging to provide high-quality nursing, medical rehabilitation, spiritual comfort, and other services, so it is necessary to increase the training for comprehensive assessment, rehabilitation, and healthcare, chronic management, geriatric nutrition, humanistic care, etc. In total, $83.6 \%$ of geriatric nursing staff have participated in on-the-job training, but only $53.4 \%$ thought that the content was helpful for work, and only $38.9 \%$ were very satisfied with the training. In addition to the training content, these observations may also be related to the methods and arrangements for training. Both professional medical staff and nursing staff suggest that more practical training should be provided. Such training can improve the effectiveness of learning, strengthen memory, and when combined with normal work routines, improve the quality of clinical nursing $[28,29]$. In terms of training arrangements, the most requested frequency of training for caregivers was once per quarter, using phased training, the duration of which should be between 30 and $60 \mathrm{~min}$. It is clear that formation of geriatric healthcare talent teams is a long process, which should be gradual, not too rapid, and utilizing processes that do not ignore quality.

The level of education of nursing staff in the present survey was generally low, with only $8.6 \%$ having a college degree or above, and only $53.5 \%$ having work qualification certificates. This may be related to a reduction in the employment threshold caused by the considerable lack of geriatric nursing staff. According to surveys, more than 10 million care staff are required in China, while the actual number of employees is less than 1 million [30]. In this regard, the government can, through the use of policy guidance, attract more highquality talent to enter the field of geriatric healthcare, improve the overall professional level of the industry, and establish and improve vocational qualification certification and training systems. Professional and technical personnel engaged in healthcare should have obtained the relevant healthcare qualifications, while those without those qualifications should instead have the corresponding job training certification. In addition, the financial and social status of the employees should be improved so that occupational attraction is improved. The salaries and benefits of healthcare workers should be linked to their professional skill levels and the duration and difficulty of the work, so that those who are highly skilled earn more, as should those that work hard. On the other hand, colleges and universities are strongly advocated to offer major degree subjects related to geriatric healthcare, introduce incentive schemes for healthcare personnel training, attract students to study geriatric healthcare through a reduction in tuition fees, and provide scholarships and employment subsidies, etc., to improve the reserve of talent. 
To make the results more representative, we selected research objects from different settings. However, the number of participants was unbalanced. There were more participants in nursing homes than in communities or geriatric hospitals, which may have led to selection bias. In addition, Although the study included as many participants as possible, all were from northeast China, and so the findings may not be generalizable to other population centers. There is still a need for additional cross-regional, large-sample, multi-center studies to better understand the demand for care services for the older population and the training needs of their care workers.

\section{Conclusions}

As the demands of the aging population are clearly increasing, the demand structure has been transformed from survival to one of development. The diverse needs of old people have a greater requirement for cultural knowledge, with greater business skills, service level, qualifications, and professional quality of healthcare workers, so training healthcare service talent is urgently required to build healthcare service capacity. The Government should consider enhanced top-level design, and provide guidance so that healthcare service personnel training is developed. To improve the effectiveness and quality of the training, various methods can be explored, such as scenario simulation and practical demonstrations, etc., closely combined with clinical work, with multi-disciplinary training that is based on the needs of older people. In addition, cooperation with colleges and universities should be encouraged to strengthen the reserve of talent and cultivate the professional quality of geriatric healthcare personnel.

\section{Acknowledgements}

We would like to extend our sincere gratitude to all participants, directors of nursing homes and hospitals for their great assistance and cooperation.

\section{Authors' contributions}

GQ contributed to the study design. YL conducted data collection. JZ provided data analysis. SL wrote the main manuscript text. AW revised the manuscript. All authors read and approved the final manuscript.

\section{Funding}

The cost of data collection such as materials and transportation costs for this research was funded by the Chinese Academy of Engineerring (No: 2020-XZ20).

\section{Availability of data and materials}

The datasets used and analyzed during the current study are available from the corresponding author upon reasonable request.

\section{Declarations}

\section{Ethics approval and consent to participate}

Ethical clearance had been granted to the authors prior to the study by the Research Ethics Committee of the Peking Union Medical College Hospital (No: S-K1294). Signed written consent was obtained from participants prior to participation. All methods were performed in accordance with the relevant guidelines and regulations.
Consent for publication

Not applicable.

\section{Competing interests}

The authors declare that they have no competing interests.

\section{Author details}

${ }^{1}$ Department of Nursing, First Affiliated Hospital of China Medical University, Liaoning, Shenyang, China. ${ }^{2}$ Department of Orthopedics, Peking Union Medical College Hospital, Beijing, China.

Received: 10 July 2021 Accepted: 4 January 2022

Published online: 19 January 2022

\section{References}

1. World Health Organization. Ageing-and health. 2018. https://www.ncl.ac.uk/ who-we-are/strengths/ageing-health/. Accessed 5 Feb 2018.

2. China Development Research Foundation. China development report 2020: trends and policies in China's aging population. 2020. http://language.china daily.com.cn/a/202006/01/WS5ed46379a310a8b241159ce5.html. Accessed 22 May 2020.

3. Zhang LW, Fang Y. Predicting the scale of disability and the cost of care for the elderly in urban and rural China during 2020-2050. Chin J Health Stat. 2021;38:39-42.

4. Wang LM, Chen ZH, Zhang M, et al. Study on the prevalence and burden of chronic diseases in elderly population in China. Chin J Epidemiol. 2019;3: 277-83

5. Abdi S, Spann A, Borilovic J, de Witte L, Hawley M. Understanding the care and support needs of older people: a scoping review and categorisation using the WHO international classification of functioning, disability and health framework (ICF). BMC Geriatr. 2019;19:195.

6. Li F, Otani J. Financing elderly people's long-term care needs: evidence from China. Int J Health Plan Manag. 2018;33:479-88.

7. Feng Z, Liu C, Guan X, Vincent M. China's rapidly aging population creates policy challenges in shaping a viable long-term care system. Health Aff. 2012:31:2764-73.

8. Wong YC, Leung J. Long-term care in China: issues and prospects. J Gerontol Soc Work. 2012:55(7):570-86.

9. Qian Y, Qin W, Zhou C, Ge D, Zhang L, Sun L. Utilisation willingness for institutional care by the elderly: a comparative study of empty nesters and non-empty nesters in Shandong, China. BMJ Open. 2018;8:e22324.

10. Beard JR, Officer A, de Carvalho IA, Sadana R, Pot AM, Michel JP, et al. The World report on ageing and health: a policy framework for healthy ageing Lancet. 2016;387:2145-54.

11. Jong L, Plöthner M, Stahmeyer JT, Eberhard S, Zeidler J, Damm K. Informal and formal care preferences and expected willingness of providing elderly care in Germany: protocol for a mixed-methods study. BMJ Open. 2019;9: e023253.

12. Hu B. Projecting future demand for informal care among older people in China: the road towards a sustainable long-term care system. Health Econ Policy Law. 2019;14:61-81.

13. Wang J, Wang Y, Cai H, Zhang J, Pan B, Bao G, et al. Analysis of the status quo of the elderly's demands of medical and elderly care combination in the underdeveloped regions of Western China and its influencing factors: a case study of Lanzhou. BMC Geriatr. 2020;20:338.

14. Zhu H. Unmet needs in long-term care and their associated factors among the oldest old in China. BMC Geriatr. 2015;15:46.

15. Xu JL, Huang SX, Qian XQ. Study on the problems and countermeasures of nursing nursing staff training in colleges and universities. Nursing Res. 2020; 34:4114-7.

16. Nations TU. Population aging and its social and economic consequences. 1956.

17. National Bureau of Statistics. The population of Northeast China has decreased by $1.2 \%$ in 10 years, and the aging degree is higher than the national average level. In: The seventh national census main data results conference. 2021. p. 231-245.

18. Hu H, Si Y, Li B. Decomposing inequality in long-term care need among older adults with chronic diseases in China: a life course perspective. Int Environ Res Public Health. 2020;17:2559. 
19. Gordievskaia EO, Kosterina ZV, Gordievskaia OV, Starobina EM, Klimacheva SB. Effectiveness of measures for socio-psychological rehabilitation of elderly persons in the hospital. Adv Gerontol. 2020;33(1):165-71.

20. Hao X, Gu J, Ying X, Bo T, Fu W. Social support and care needs of the disabled elderly population: an empirical study based on survey data from Beijing, China. Biosci Trends. 2017;11:507-15.

21. Harrison M, Ryan T, Gardiner C, Jones A. Psychological and emotional needs, assessment, and support post-stroke: a multi-perspective qualitative study. Topic Stroke Rehabil. 2017;24:119-25.

22. Poscia A, Stojanovic J, La Milia DI, Duplaga M, Grysztar M, Moscato U, et al. Interventions targeting loneliness and social isolation among the older people: an update systematic review. Exp Gerontol. 2018;102:133-44.

23. Fakoya OA, Mccorry NK, Donnelly M. Loneliness and social isolation interventions for older adults: a scoping review of reviews. BMC Public Health. 2020:20(1):129.

24. Medical Administration and Hospital Authority. Policy interpretation on further promoting the pilot work of "Internet + Nursing Service". 2020. http://www.nhc.gov.cn/yzygj/s7652ms/202012/80e3d18bad754895985654 0569370e75.shtml. Accessed 14 Dec 2020.

25. Chen X, Zhang Y, Hou L, Shen Y, Li J, Dong B. Analysis of risk factors for cognitive dysfunction in disabled elderly patients in Chengdu, China. Med Sci Monit. 2020;26:e923590.

26. Dauth $C$, Lang J. Can the unemployed be trained to care for the elderly? The effects of subsidized training in elderly care. Health Econ. 2019;28(4): $543-55$

27. Song $\mathrm{P}$, Tang $\mathrm{W}$. The community-based integrated care system in Japan: health care and nursing care challenges posed by super-aged society. Biosci Trend. 2019;13(3):279-81

28. Polonio-López B, Triviño-Juárez JM, Corregidor-Sánchez Al, ToledanoGonzález A, Rodríguez-Martínez MC, Cantero-Garlito P, et al. Improving selfperceived emotional intelligence in occupational therapy students through practical training. Front Psychol. 2019;10:920.

29. Swart R, Hall M. From clinical practice to academic student instruction: understanding the clinical instructor's perspective using a mixed-methods approach. Can J Nurs Res. 2021;53:114-23.

30. Mao Y. The training of nursing staff and the participation of Red Cross Society. Zhejiang University; 2019

\section{Publisher's Note}

Springer Nature remains neutral with regard to jurisdictional claims in published maps and institutional affiliations.

Ready to submit your research? Choose BMC and benefit from:

- fast, convenient online submission

- thorough peer review by experienced researchers in your field

- rapid publication on acceptance

- support for research data, including large and complex data types

- gold Open Access which fosters wider collaboration and increased citations

- maximum visibility for your research: over $100 \mathrm{M}$ website views per year

At $\mathrm{BMC}$, research is always in progress.

Learn more biomedcentral.com/submissions 